\title{
Ileal Ulcer, CTCAE
}

National Cancer Institute

\section{Source}

National Cancer Institute. Ileal Ulcer, CT CAE. NCI Thesaurus. Code C57826.

A disorder characterized by a circumscribed, erosive lesion on the mucosal surface of the ileum. 